\title{
Terapia fotodinâmica no controle de Xanthomonas campestris pv. campestris in vitro e no tratamento de sementes de canola naturalmente contaminadas
}

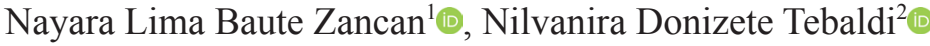

\begin{abstract}
${ }^{1}$ Mestre em Agronomia, Universidade Federal de Uberlândia, Av. Amazonas s/n, Bloco 2E-119, Campus Umuarama, CEP 38.400-902, Uberlândia, MG, Brasil. ${ }^{2}$ Professora Associada, do Instituto de Ciências Agrárias, da Universidade Federal de Uberlândia, Av. Amazonas s/n, Bloco 2E-119, Campus Umuarama, CEP 38.400-902, Uberlândia, MG, Brasil

Autor para correspondência: Nilvanira Donizete Tebaldi (nilvanira.tebaldi@ufu.br)

Data de chegada: 15/05/2018. Aceito para publicação em: 20/08/2020.
\end{abstract}

$10.1590 / 0100-5405 / 199134$

\section{RESUMO}

Zancan, N.L.B.; Tebaldi, N.D. Terapia fotodinâmica no controle de Xanthomonas campestris pv. campestris in vitro e no tratamento de sementes de canola naturalmente contaminadas. Summa Phytopathologica, v.46, n.4, p.327-332, 2020.

A cultura da canola (Brassica napus L. var. oleifera) foi recentemente introduzida na região do Triângulo Mineiro e Alta Paranaíba, MG. A podridão negra causada pela bactéria Xanthomonas campestris pv. campestris (Xcc) é uma das principais doenças da cultura. A bactéria é disseminada pelas sementes e métodos alternativos de controle devem ser avaliados. Diante disso, o objetivo deste trabalho foi avaliar o uso da terapia fotodinâmica, com os corantes Azul de Metileno (AM) e Azul de Toluidina (AT), sob à irradiação, na inibição do crescimento de Xcc in vitro e no tratamento de sementes de canola naturalmente contaminadas com a bactéria. A suspensão bacteriana de Xcc foi tratada com os corantes AM, AT e associação deles (AM+AT) nas concentrações 25, 50 e $100 \mu \mathrm{mol} \mathrm{L}^{-1}$, irradiadas ou não, e cultivada em meio de cultura, em seguida foi avaliado o número de unidades formadoras de colônias. Sementes de três genótipos de canola foram tratadas com $\mathrm{NaCl} 0,45 \%$ (Testemunha), AM, AT e $\mathrm{AM}+\mathrm{AT}$, nas concentrações 100,50 e $25 \mu \mathrm{mol} \mathrm{L}^{-1}$, respectivamente, irradiadas ou não. A porcentagem de germinação das sementes, índice de velocidade de emergência, porcentagem de emergência de plântulas e o controle da bactéria nas sementes foram avaliados. Os corantes AM, AT e AM+AT, nas concentrações 100,50 e $25 \mu \mathrm{mol} \mathrm{L}^{-1}$ respectivamente, sob irradiação inibiram o crescimento de Xcc in vitro. A combinação dos corantes $\mathrm{AM}+\mathrm{AT}$ a $25 \mu \mathrm{mol} \mathrm{L} \mathrm{L}^{-1}$ pode ser utilizada no tratamento das sementes de canola. O controle da bactéria Xcc em sementes de canola naturalmente contaminada não foi possível ser determinada com os diferentes corantes.

Palavras-chave: Azul de metileno, azul de toluidina, Brassica napus L. var. oleifera, fotossensibilizador, inativação de micro-organismos.

\section{ABSTRACT}

Zancan, N.L.B.; Tebaldi, N.D. Photodynamic therapy in the control of Xanthomonas campestris pv. campestris in vitro and naturally contaminated canola seeds. Summa Phytopathologica, v.46, n.4, p.327-332, 2020.

Canola (Brassica napus L. var. oleifera) crop was recently introduced in the regions of "Triângulo Mineiro" and "Alta Paranaíba", Minas Gerais State, Brazil. Black rot, caused by the bacterium Xanthomonas campestris pv. campestris (Xcc), is one of the major diseases affecting this crop. The bacterium is disseminated via seeds and alternative control methods should be investigated. Therefore, the objective of this study was to evaluate the use of photodynamic therapy with the dyes Methylene Blue (MB) and Toluidine Blue (TB), under irradiation, on Xcc growth inhibition in vitro and on the treatment of canola seeds naturally contaminated with the bacterium. Xcc bacterial suspension was treated with $\mathrm{MB}, \mathrm{TB}$ and their association $(\mathrm{MB}+\mathrm{TB})$ at the concentrations
25, 50 and $100 \mu \mathrm{mol} \mathrm{L}^{-1}$, irradiated or not, and cultivated on culture medium; then, the number of colony-forming units was assessed. Seeds of three canola genotypes were treated with $0.45 \% \mathrm{NaCl}$ (Control), $\mathrm{MB}$, TB and MB+TB, at the concentrations 100,50 and $25 \mu \mathrm{mol} \mathrm{L}^{-1}$, respectively, irradiated or not. Seed germination percentage, emergence speed rate, seedling emergence percentage and control of bacteria in the seeds were evaluated. $\mathrm{MB}, \mathrm{TB}$ and $\mathrm{MB}+\mathrm{TB}$, at 100,50 and $25 \mu \mathrm{mol} \mathrm{L}{ }^{-1}$, respectively, under irradiation, inhibited Xcc growth in vitro. The combination of dyes $\mathrm{MB}+\mathrm{TB}$, at $25 \mu \mathrm{mol} \mathrm{L}^{-1}$, can be used in the treatment of canola seeds. Control of the bacterium Xcc in naturally contaminated canola seeds could not be determined with the different dyes.

Keywords: Methylene blue, toluidine blue, Brassica napus L. var. oleifera, photosensitizer, microorganism inactivation.

A cultura da canola (Brassica napus L. var. oleifera) foi introduzida no Triângulo Mineiro e Alta Paranaíba, MG, em 2014, sendo a terceira oleaginosa mais cultivada no mundo (26). Seus cultivos destina à extração de óleo comestível, produção de biodiesel e ao uso do farelo na ração animal (27).

A podridão negra, causada pela bactéria Xanthomonas campestris pv. campestris (Pammel 1895) Dowson 1939 (Xcc) é uma das principais doenças da cultura, ocasionando perdas na produtividade (30). A bactéria é disseminada pelas sementes, que pode ser introduzida em novas áreas de cultivo, levando a ocorrência de epidemias.

O controle químico da bactéria não é eficiente (22) e medidas alternativas de controle do patógeno nas sementes devem ser avaliadas, como o uso da terapia fotodinâmica.

A terapia fotodinâmica consiste na associação de um corante sensível à luz, o fotossensibilizador que é ativado em um comprimento de onda específico. Após exposição microbiana a esta energia luminosa, o fotossensibilizador é energizado provocando a formação de espécies reativas de oxigênio, responsáveis pela inativação do micro-organismo (4). Os fotossensibilizadores podem causar danos severos ao DNA, à membrana celular e à oxidação de compostos orgânicos insaturados, como os lipídeos (19), além de inativarem enzimas essenciais ao patógeno $(20,21)$. 
Essa técnica tem apresentado resultados promissores na área médica e odontológica, como no tratamento de raízes de canais de dentes humanos contaminados com Enterococcus faecalis com redução de $99,9 \%$ da bactéria (8). A terapia fotodinâmica foi introduzida na área agrícola $(7,24)$, como uma medida alternativa de controle de bactérias fitopatogênicas.

Assim, o objetivo deste trabalho foi avaliar o uso da terapia fotodinâmica com os corantes Azul de Metileno, Azul de Toluidina e a combinação deles, irradiados ou não, no controle de Xcc in vitro e no tratamento de sementes de canola naturalmente contaminadas, para o controle da bactéria.

\section{MATERIAL E MÉTODOS}

Os ensaios foram conduzidos no Laboratório de Bacteriologia Vegetal (LABAC), no Laboratório de Sementes e em casa de vegetação, do Instituto de Ciências Agrárias (ICIAG), da Universidade Federal de Uberlândia (UFU) - MG.

\section{Preparo da suspensão bacteriana}

O isolado UFU F64 de Xanthomonas campestris pv. campestris (Xcc) pertencente à coleção de trabalho do LABAC, do ICIAG, da UFU foi cultivado em meio de cultura $523(11)$, a $28^{\circ} \mathrm{C}$ por 48 horas.

A suspensão bacteriana foi preparada em $\mathrm{NaCl}(0,45 \%)$ e ajustada em espectrofotômetro $\left(\mathrm{OD}_{550}=0,5\right)$ para a concentração de $1 \times 10^{9} \mathrm{UFC}$ $\mathrm{mL}^{-1}(16)$.

Terapia fotodinâmica na inibição do crescimento de Xanthomonas campestris pv. campestris in vitro

Para a inativação da suspensão bacteriana in vitro utilizou-se os corantes Azul de Metileno (AM), Azul de toluidina (AT) e a associação destes (AM+AT) (1:1), nas concentrações 25, 50 e $100 \mu \mathrm{mol} \mathrm{L} \mathrm{L}^{-1}$, em solução de $\mathrm{NaCl}(0,45 \%)$ e esterilizados em autoclave por 30 minutos a $120^{\circ} \mathrm{C}$. Para a testemunha foi utilizada a solução de $\mathrm{NaCl}(0,45 \%)$.

Em microtubos $(1,5 \mathrm{~mL})$ colocou-se $100 \mu \mathrm{L}$ da suspensão bacteriana e $900 \mu \mathrm{L}$ de cada corante, nas diferentes concentrações. Para a testemunha utilizou $100 \mu \mathrm{L}$ da suspensão bacteriana e $900 \mu \mathrm{L}$ da solução de $\mathrm{NaCl}(0,45 \%)$. Todos os microtubos foram recobertos com papel alumínio e incubados em estufa a $28{ }^{\circ} \mathrm{C}$ por $20 \mathrm{~min}$. Posteriormente, parte dos microtubos foram colocados a $5 \mathrm{~cm}$ de distância da fonte de iluminação (Equipamento AMS-II, sistema de LED de alta potência, emissão $652 \mathrm{~nm}$ ) e irradiados por 20 minutos. Os demais microtubos foram mantidos no escuro em temperatura ambiente $\left(25^{\circ} \mathrm{C}\right)$.

Em seguida a suspensão bacteriana foi diluída em série $\left(10^{-2} \mathrm{a}\right.$ $\left.10^{-7}\right)$, em solução de $\mathrm{NaCl}(0,45 \%)$, cultivada em meio de cultura 523 , em placas de Petri, incubadas a $28{ }^{\circ} \mathrm{C}$ por 4 dias. Posteriormente, o número de unidades formadoras de colônias $\left(\mathrm{UFC} \mathrm{mL}^{-1}\right.$ ) foi avaliada pela contagem de colônias formadas.

$\mathrm{O}$ experimento foi conduzido em delineamento de blocos inteiramente casualizados, com três repetições e em um arranjo fatorial $3 \times 3 \times 2+2$ (corantes $\times$ concentrações $\times$ luminosidade + adicionais).

\section{Terapia fotodinâmica no tratamento de sementes de canola}

As sementes dos genótipos de canola Terola 10A40 SS (Serra do Salitre, MG, 2014), Hyola 61 (Área experimental, RS, 2014) e Terola 10A40 MT (Área experimental, MT, 2013) naturalmente contaminadas com Xcc, foram tratadas com os corantes AM, AT e
$\mathrm{AM}+\mathrm{AT}$, nas concentrações 100,50 e $25 \mu \mathrm{mol} \mathrm{L}{ }^{-1}$, respectivamente. Para a testemunha as sementes foram tratadas com $\mathrm{NaCl} 0,45 \%$. Testes preliminares de detecção da bactéria usando extrato de sementes (1.000), em meio cultura confirmaram a presença da bactéria nas sementes dos genótipos canola utilizadas neste trabalho.

As sementes de cada genótipo ( 800 sementes) foram colocadas em placas de Petri, e adicionado $20 \mathrm{~mL}$ de cada corante ou $\mathrm{NaCl} 0,45 \%$ (testemunha) e, em seguida, as placas foram incubadas em estufa a $28{ }^{\circ} \mathrm{C}$ por 20 minutos. Posteriormente, as sementes foram colocadas a $5 \mathrm{~cm}$ de distância da fonte de iluminação (Equipamento AMS-II, sistema de LED de alta potência, emissão $652 \mathrm{~nm}$ ) e irradiadas por 20 minutos. As sementes não irradiadas foram mantidas no escuro em temperatura ambiente.

Controle de Xanthomonas campestris pv. campestris em sementes de canola

Para o controle de Xcc em sementes de canola, foram utilizadas 200 sementes de cada genótipo, com oito repetições de 25 sementes. As sementes foram tratadas com os corantes (AM, AT, AM+AT), irradiadas ou não. Para a testemunha as sementes foram tratadas com $\mathrm{NaCl}$ $0,45 \%$. O experimento foi conduzido em delineamento inteiramente casualizado, em arranjo fatorial $4 \times 2$ (3 corantes +1 testemunha $\mathrm{x}$ irradiado/escuro).

As sementes de canola foram colocadas sobre o meio de cultura semi-seletivo NSCAA (25) em placas de Petri, e incubadas em estufa a $28{ }^{\circ} \mathrm{C}$ por 72 horas. Após este período, avaliou-se o número de sementes com a presença de Xcc, determinando a porcentagem de sementes contaminadas.

\section{Teste padrão de germinação das sementes de canola}

O teste padrão de germinação foi realizado de acordo com as Regras para Análise de Sementes (RAS) (2), utilizando 200 sementes para cada tratamento. $\mathrm{O}$ experimento foi conduzido em delineamento de blocos inteiramente casualizado, com quatro repetições de 50 sementes cada, em um arranjo fatorial $4 \times 2$ (3 corantes +1 testemunha $\mathrm{x}$ irradiado/ escuro)

As sementes foram colocadas sobre duas folhas de papel mata borrão, em caixas tipo gerbox. O papel foi embebido com água, equivalente a 2,5 vezes a massa do papel seco. As sementes foram levadas ao germinador à temperatura de $20-30{ }^{\circ} \mathrm{C} \pm 2$, com fotoperíodo de $8 \mathrm{~h}$ luz/16 h escuro (2).

As avaliações foram realizadas pela contagem de plântulas normais emergidas, sendo a primeira e a última contagem, no quinto e sétimo dia, respectivamente. Os resultados foram expressos em \% de germinação, conforme critérios estabelecidos pela RAS (2).

Índice de velocidade de emergência e emergência de plântulas

$\mathrm{O}$ experimento foi realizado em casa de vegetação, utilizando-se 200 sementes, com quatro repetições de 50 sementes. As sementes foram semeadas em bandejas de isopor $(25 \mathrm{~cm} \times 20 \mathrm{~cm})$ contendo areia estéril. $\mathrm{O}$ experimento foi conduzido em delineamento de blocos casualizados, em um arranjo fatorial 4 × 2 ( 3 corantes +1 testemunha $\mathrm{x}$ irradiado/escuro).

A contagem de plântulas (cotilédones visíveis) ocorreu diariamente, a partir do segundo dia até o nono dia após a semeadura. Ao final das avaliações com o número de plântulas emergidas, calculou-se o índice de velocidade de emergência (IVE) pela fórmula descrita por Maguire (15).

A emergência de plântulas foi avaliada pelo número de sementes 
emergidas, no nono dia após a semeadura, calculando-se a porcentagem de plântulas emergidas.

\section{Análise estatística}

Os dados obtidos foram submetidos ao teste de pressuposições, teste de normalidade (Shapiro Wilk), homogeneidade (Levene) e aditividade, pelo programa estatístico SPSS Statistics vs. 20 (10). As médias dos tratamentos foram comparadas pelo teste de Tukey a 5\% de probabilidade, as análises foram realizadas através do programa estatístico SISVAR versão 5.30 (6).

\section{RESULTADOS E DISCUSSÃO}

Terapia fotodinâmica na inibição do crescimento de Xanthomonas campestris pv. campestris in vitro

O tratamento da suspensão bacteriana com os corantes azul de metileno (AM), azul de toluidina (AT) e a mistura de ambos (AM+AT), nas três diferentes concentrações 25,50 e $100 \mu \mathrm{mol} \mathrm{L}^{-1}$ (Tabela 1), quando não irradiado, no escuro, proporcionaram o crescimento da bactéria em meio de cultura, ou seja, estes tratamentos não erradicaram a bactéria. No entanto, quando a suspensão bacteriana foi irradiada com o uso dos corantes AM a $100 \mu \mathrm{mol} \mathrm{L}^{-1}$, AT a 50 e $100 \mu \mathrm{mol} \mathrm{L}^{-1} \mathrm{e}$ $\mathrm{AM}+\mathrm{AT}$ nas três concentrações 25,50 e $100 \mu \mathrm{mol} \mathrm{L}^{-1}$ houve inibição do crescimento ou a eliminação total das células bacterianas. A suspensão bacteriana, testemunha no escuro $\left(1,2 \times 10^{8} \mathrm{UFC} \mathrm{mL}^{-1}\right)$ e irradiada $\left(1,2 \times 10^{5} \mathrm{UFC} \mathrm{mL}^{-1}\right)$ houve o crescimento bacteriano.

Somente a combinação entre corantes $(\mathrm{AM}+\mathrm{AT})$ nas três diferentes concentrações, quando irradiado, inibiu o crescimento da bactéria, demonstrando que a interação entre os corantes apresentou efeito potencializado.

Os corantes AM e AT foram eficazes na inativação da bactéria Xanthomonas spp. erradicando completamente o crescimento bacteriano (7) e quando os corantes foram associados apresentaram maior efeito tóxico sobre a bactéria.

Longo \& Azevedo (13) encontraram resultados semelhantes a este trabalho, com o AM nas concentrações 25 e $50 \mu \mathrm{mol} \mathrm{L}^{-1}$ não apresentou efeito bactericida a Escherichia coli. Em contrapartida, a combinação deste corante com irradiação a laser promoveu redução significativa do número de colônias. Tal resultado mostra que, para o sucesso da terapia fotodinâmica é necessário à junção dos fatores luz e agente fotossensibilizador.

Os corantes fotossensíveis absorvem luz em um comprimento de onda específico, o oxigênio presente é transformado para o estado excitado, reagindo com o substrato local, formando espécies reativas de oxigênio, reagindo com a parede celular, ácidos nucleicos, peptídeos, lipídeos e proteínas (5), e assim promovendo a morte celular por apoptose ou necrose $(14,18)$. Esses corantes possuem a capacidade de passar pela membrana celular, pelos canais de proteínas, presentes nas bactérias Gram-negativas (28).

O corante AM possui afinidade por proteínas presentes na parede celular e na membrana citoplasmática bacteriana (29). O AT liga-se aos polifosfatos da membrana, sendo capaz de produzir danos moleculares para proteínas, lipídeos e também ao mesossomo (geração de energia), sendo considerado um excelente destruidor da membrana, pela sua ação fotodinâmica (28).

Controle de Xanthomonas campestris pv. campestris em sementes de canola

Nas sementes inteiras de canola dos genótipos Terola 10A40 (2014), Hyola 61(2014) e Terola 10A40 (2013) tratadas com AM (100 $\left.\mu \mathrm{mol} \mathrm{L}{ }^{-1}\right)$, AT $\left(50 \mu \mathrm{mol} \mathrm{L}^{-1}\right), \mathrm{AM}+\mathrm{AT}\left(25 \mu \mathrm{mol} \mathrm{L}{ }^{-1}\right)$ e sem tratamento (testemunha), não foi detectada a presença de Xcc. A não detecção da bactéria na testemunha deve-se provavelmente à baixa taxa de infecção e o reduzido número de sementes utilizados (200 sementes), uma vez que as sementes estavam naturalmente contaminadas, determinado por testes preliminares do extrato de 1.000 sementes. Os corantes também podem ter sido efetivos no controle da bactéria nas sementes, onde não houve a detecção.

A superfície das sementes pode abrigar diversos patógenos e a porcentagem de bactérias presentes nas sementes é muito baixa, quase sempre menor que 1\% (23), o que dificulta a detecção, necessitando assim, nos testes um maior número de sementes. O desenvolvimento de uma doença está relacionado com a concentração de inóculo presente nas sementes, levando a transmissão semente-planta $(9,17)$.

Sementes de tomate inoculadas com Xanthomonas spp. quando tratadas com a associação dos corantes AM+AT a $50 \mu \mathrm{mol} \mathrm{L} \mathrm{L}^{-1}$ erradicaram $100 \%$ da bactéria (7), demonstrando que a terapia fotodinâmica foi eficiente para o controle de bactéria nas sementes, sendo uma medida inovadora no tratamento de sementes e no controle de fitobactérias.

Germinação, índice de velocidade de emergência e emergência de plântulas de sementes de canola

Para a porcentagem de germinação de sementes dos diferentes genótipos de canola, tratadas com diferentes corantes, irradiadas ou não (Tabela 2), houve diferença significativa entre os corantes e o genótipo Terola 10A40 SS, as sementes não tratadas (testemunha) e as sementes tratadas com AM+AT $\left(25 \mu \mathrm{mol} \mathrm{L}^{-1}\right)$ apresentaram $80 \mathrm{e}$ $77 \%$ de germinação, respectivamente, diferindo significativamente dos corantes AM $100 \mu \mathrm{mol} \mathrm{L}^{-1}(64 \%)$ e AT $50 \mu \mathrm{mol} \mathrm{L}^{-1}$ (70\%) (Tabela 2).

Tabela 1. Inibição do crescimento de Xanthomonas campestris pv. campestris in vitro, em unidades formadoras de colônia (UFC mL ${ }^{-1}$ ), com corantes fotodinâmicos em diferentes concentrações $\left(25,50\right.$ e $\left.100 \mu \mathrm{mol} \mathrm{L}^{-1}\right)$, sob condições de escuro ou irradiado. Uberlândia - MG, 2017.

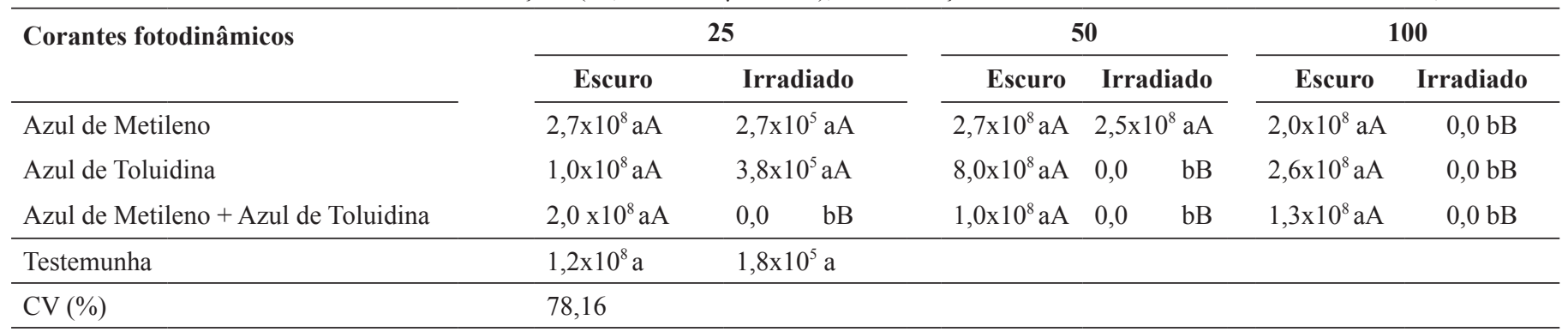

Médias seguidas por letras distintas, minúscula na coluna e maiúscula na linha, diferem entre si pelo teste de Tukey a 0,05 de significância. 
Para o genótipo Terola 10A40 MT (Tabela 2), o tratamento das sementes com o corante AM $\left(100 \mu \mathrm{mol} \mathrm{L}^{-1}\right)$ na condição escuro apresentou $78 \%$ de germinação das sementes diferindo significativamente dos corantes AM+AT $25 \mu \mathrm{mol} \mathrm{L}{ }^{-1}$ (96\%), AT 50 $\mu \mathrm{mol} \mathrm{L}-1$ (93\%) e da testemunha (92\%). No entanto, quando as sementes foram tratadas com os diferentes corantes e irradiadas ( 89 a 91\%) não diferiram significativamente da testemunha ( $89 \%)$ na germinação das sementes. Porém, as sementes tratadas com o corante AM $100 \mu \mathrm{mol}$ $\mathrm{L}^{-1} \mathrm{e}$ irradiadas (89\%) diferiram significativamente das sementes não irradiadas (78\%). No entanto, o tratamento das sementes com AM+AT $25 \mu \mathrm{mol} \mathrm{L}{ }^{-1}$ houve um aumento na porcentagem de germinação das sementes (96\%), quando comparado com a testemunha (92\% escuro e $89 \%$ irradiado).

Para o genótipo Hyola 61 não houve interação significativa em nenhuma variável, na porcentagem de germinação, variando de 78 a $86 \%$.

De acordo com Ferreira (7) sementes de tomate tratadas com AM ou AT a $50 \mu \mathrm{mol} \mathrm{L}^{-1} \mathrm{e}$ irradiadas apresentaram maior porcentagem de germinação do que a testemunha, resultados semelhantes ao obtido neste trabalho para o genótipo Terola10A40 MT, com AT a $50 \mu \mathrm{mol}$ $\mathrm{L}^{-1}$. No entanto, houve uma redução na porcentagem de germinação das sementes de tomate (7) quando tratadas com a combinação dos corantes $\mathrm{AM}+\mathrm{AT}$ a $50 \mu \mathrm{mol} \mathrm{L}{ }^{-1}$, divergindo dos resultados obtidos neste trabalho, com o uso dos corantes associados AM+AT na concentração de $25 \mu \mathrm{mol} \mathrm{L}^{-1}$, para as sementes do genótipo Terola 10A40 MT, onde houve um aumento na porcentagem de germinação, provavelmente devido a concentração dos corantes utilizada.

A formação de espécies reativas de oxigênio ativadas pelos corantes fotossensibilizadores podem danificar os componentes celulares das bactérias $(19,20,21)$, enquanto que nas sementes, as espécies reativas de oxigênio podem estar presentes nas diferentes fases de desenvolvimento da mesma (12) e qualquer concentração fora do intervalo estabelecido pode impedir a germinação ou diminuir o vigor das sementes (1).

Também vale ressaltar a possibilidade de os corantes fotossensibilizadores impedirem o fluxo de água pelos poros da proteína aquaporina, responsável pelo transporte de água para a semente, dificultando a germinação (3).

Para o índice de velocidade de emergência (IVE) (Tabela 3), as sementes de canola tratadas com o corante AT $\left(50 \mu \mathrm{mol} \mathrm{L} \mathrm{L}^{-1}\right)$ apresentaram os menores índices, independente do genótipo, quando comparado com demais corantes e a testemunha, irradiado e escuro. Os maiores IVE foram observados na testemunha, exceto no genótipo Terola 10A40 SS irradiado $(5,63)$.

No entanto, para o índice de velocidade de emergência de sementes de tomate, Ferreira (7) observou que não houve diferença entre os corantes AM e AT a $50 \mu \mathrm{mol} \mathrm{L}{ }^{-1}$, e os corantes não reduziram a qualidade fisiológica das sementes de tomate.

Para porcentagem de emergência de plântulas (Tabela 4) do genótipo Hyola 61 não houve diferença significativa entre a testemunha $(84 \%)$ e as sementes tratadas com os corantes AM+AT (81\%) e AM $(62 \%)$, no entanto, diferiram significativamente do corante AT (36\%).

Tabela 2. Porcentagem de germinação de sementes, de diferentes genótipos de canola, tratadas com diferentes corantes, irradiadas ou não. Uberlândia - MG, 2017.

\begin{tabular}{|c|c|c|c|}
\hline \multirow{3}{*}{ Corantes } & \multicolumn{3}{|c|}{ Genótipos de Canola } \\
\hline & \multirow{2}{*}{ Terola 10A40 SS } & \multicolumn{2}{|c|}{ Terola 10A40 MT } \\
\hline & & Escuro & Irradiado \\
\hline AM $100 \mu \mathrm{mol} \mathrm{L}^{-1}$ & $64 c$ & $78 \mathrm{bB}$ & $89 \mathrm{aA}$ \\
\hline AT $50 \mu \mathrm{mol} \mathrm{L}^{-1}$ & $70 \mathrm{bc}$ & $93 \mathrm{aA}$ & $91 \mathrm{aA}$ \\
\hline $\mathrm{AM}+\mathrm{AT} 25 \mu \mathrm{mol} \mathrm{L}-1$ & $77 \mathrm{ab}$ & $96 \mathrm{aA}$ & $96 \mathrm{aA}$ \\
\hline $\mathrm{CV}(\%)$ & 12,51 & & \\
\hline
\end{tabular}

Médias seguidas por letras distintas, minúsculas na coluna e maiúsculas na linha, diferem entre si a 0,05 de significância pelo teste de Tukey. AM: Azul de Metileno; AT: Azul de Toluidina.

Tabela 3. Índice de velocidades de emergência (IVE) de diferentes genótipos de canola, tratadas com diferentes corantes, irradiadas ou não, em condições de casa de vegetação. Uberlândia - MG, 2017.

Genótipos de canola

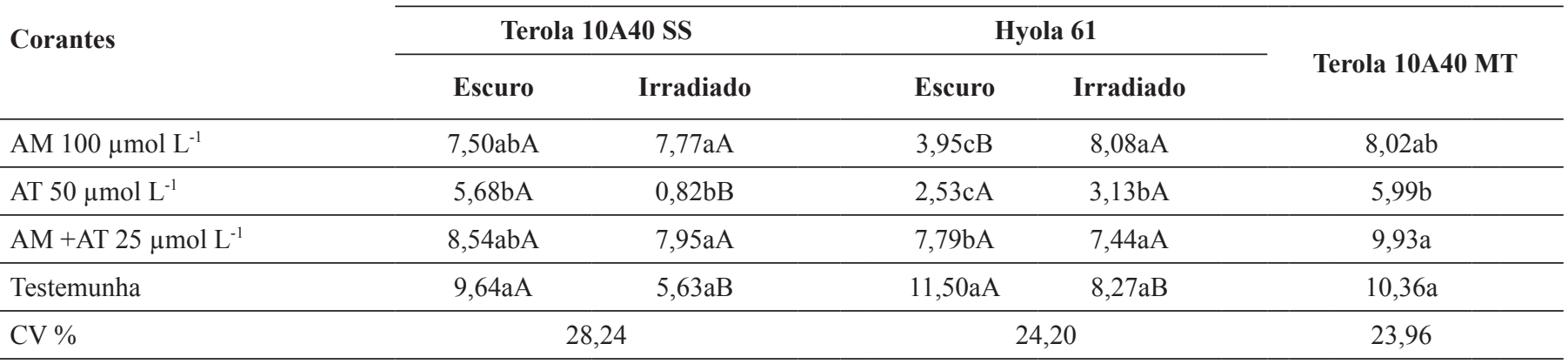

Médias seguidas por letras distintas, minúsculas na coluna e maiúsculas na linha, diferem entre si a 0,05 de significância pelo teste de Tukey. AM: Azul de Metileno; AT: Azul de Toluidina. 
Tabela 4. Porcentagem de emergência de plântulas de diferentes genótipos de canola, tratadas com diferentes corantes, irradiadas ou não, em condições de casa de vegetação. Uberlândia - MG, 2017.

\begin{tabular}{|c|c|c|c|c|}
\hline \multirow{2}{*}{ Corantes } & \multicolumn{4}{|c|}{ Genótipos de Canola } \\
\hline & Hyola 61 & Escuro & Irradiado & Terola 10A40 MT \\
\hline AT $50 \mu \mathrm{mol} \mathrm{L}{ }^{-1}$ & $36 \mathrm{~b}$ & $63 \mathrm{aA}$ & $11 \mathrm{bB}$ & $64 \mathrm{~b}$ \\
\hline $\mathrm{AM}+\mathrm{AT} 25 \mu \mathrm{mol} \mathrm{L}^{-1}$ & $81 \mathrm{a}$ & $81 \mathrm{aA}$ & $73 \mathrm{aA}$ & $93 \mathrm{a}$ \\
\hline $\mathrm{CV} \%$ & 24,28 & \multicolumn{2}{|c|}{24,52} & 25,15 \\
\hline
\end{tabular}

Médias seguidas por letras distintas, minúsculas na coluna e maiúsculas na linha, diferem entre si a 0,05 de significância pelo teste de Tukey.

AM: Azul de Metileno; AT: Azul de Toluidina.

No genótipo Terola 10A40 SS (Tabela 4), quando as sementes foram tratadas com o corante AT $50 \mu \mathrm{mol} \mathrm{L}^{-1}$ e irradiadas, a emergência de plântulas foi de $11 \%$, diferindo significativamente das sementes não irradiadas (63\%), enquanto que os demais tratamentos obtiveram valores acima de 54\%. Quando as sementes foram mantidas no escuro, não houve diferença significativa entre os corantes e a testemunha. A interação entre as variáveis, irradiada e escuro, nos tratamentos AT $50 \mu \mathrm{mol} \mathrm{L}{ }^{-1}$ e testemunha apresentaram diferenças, onde a irradiação afetou a emergência de plântulas.

A porcentagem de emergência de plântulas do genótipo Terola 10A40 MT foi de $93 \%$ quando as sementes foram tratadas com AM+AT $25 \mu \mathrm{mol}$ $\mathrm{L}^{-1}$, diferindo significativamente do tratamento AT $50 \mu \mathrm{mol} \mathrm{L}-1$ (64\%).

Independente dos genótipos de canola analisados, o corante AT $\left(50 \mu \mathrm{mol} \mathrm{L}{ }^{-1}\right)$ reduziu a emergência de plântulas em condições de casa de vegetação (Tabela 4). Em contrapartida, não houve diferença significativa entre os tratamentos AM $100 \mu \mathrm{mol} \mathrm{L}^{-1}$, AM+AT $25 \mu \mathrm{mol}$ $\mathrm{L}^{-1}$ e a testemunha (Tabela 4) para os todos os genótipos. A combinação dos corantes AM+AT a $25 \mu \mathrm{mol} \mathrm{L}{ }^{-1}$ aumentou a emergência de plântulas de canola, dos genótipos Terola 10A40 SS e Terola 10A40 MT, quando comparado com a testemunha.

A terapia fotodinâmica foi eficiente no controle de Xanthomonas spp. em sementes de tomate, e uma forma alternativa de controle de fitobactérias em sementes (7). O fato das sementes de canola apresentar um tegumento menos rígido, do que as sementes de tomate, e a necessidade das sementes ficarem imersas por 40 minutos em concentrações elevadas dos corantes AM ou AT, durante o tratamento, isto pode interferir na qualidade fisiológica das sementes de canola.

Diante dos resultados obtidos, novos ensaios deverão ser conduzidos utilizando concentrações reduzidas dos corantes AM e AT, no tratamento de sementes de canola. Os corantes fotossensíveis pode ser uma alternativa contra bactérias fitopatogênicas, uma vez que a utilização de agroquímicos não são eficientes.

Os corantes Azul de Metileno, Azul de Toluidina e a associação deles, nas concentrações 100, 50 e $25 \mu \mathrm{mol} \mathrm{L}^{-1}$ respectivamente, quando irradiados foram eficientes para controle de Xcc in vitro.

A combinação dos corantes Azul de Metileno e Azul de Toluidina a $25 \mu \mathrm{mol} \mathrm{L}^{-1}$ pode ser utilizada no tratamento das sementes de canola, pois não afetou sua qualidade fisiológica.

O controle da bactéria Xanthomonas campestris pv. campestris nas sementes de canola naturalmente contaminadas, com os diferentes corantes e concentrações não foi possível ser determinado.

\section{AGRADECIMENTOS}

À Coordenação de Aperfeiçoamento Pessoal de Nível Superior (CAPES) pela concessão de bolsa a primeira autora.

\section{REFERÊNCIAS}

1. Bailly, C.; El-Maarouf-Bouteau, H.; Corbineau, F. From intracellular signaling networks to cell death: the dual role of reactive oxygen species in seed physiology. Comptes Rendus Biologies, Paris, v.331, n.10, p.806814, 2008.

2. Brasil. Ministério da Agricultura, Pecuária e Abastecimento. Regras para Análise de Sementes (RAS). Brasília, DF: Mapa/Assessoria de Comunicação Social, 2009. 395p.

3. De Groot, B.L.; Grubmuller, H. Water permeation across biological membranes: mechanism and dynamics of aquaporin-1 and GlpF. Science, New York, v.294, n.5551, p.2353-2357, 2001.

4. Denis, T.G.; Dai, T.; Izikson, L.; Astrakas, C.; Anderson, R.R.; Kamblin, M.R.; Tegos, G.P. All you need is light: Antimicrobial photoinactivation as an evolving and emerging discovery strategy against infectious disease. Virulence, Austin, v.2, n.6, p.509-520, 2011.

5. Donnelly, R.F.; Mccarron, P.A.; Tunney, M. Antifungal Photodynamic Therapy. Microbiological Reasearch, Jena, v.163, n.1, p.1-12, 2008.

6. Ferreira, D.F. SISVAR: Sistema de análise de variância. Versão 5.3. Lavras, MG: UFLA, 2010.

7. Ferreira, S.F. Tratamento fotodinâmico de sementes de tomate (Solanum licopersicon MILL.), na inativação da bactéria Xanthomonas spp. 2012. 61f. Dissertação (Mestrado em Química) - Universidade Federal de Uberlândia, Uberlândia.

8. Fonseca, M.B.; Tessare Júnior, P.O.; Pallota, R.C.; Ferreira Filho, H.; Denardin, O.V.; Rapoport, A.; Dedivitis, R.A.; Veronezi, J.F.; Genovese, W.J.; Ricardo, A.L. Photodynamic therapy for root canals infected with Enterococcus faecalis. Photomedicine and Laser Surgery, Larchmont, v.26, n.3, p.209-213, 2008.

9. Hirano, S.S.; Upper, C.D. Ecology and epidemiology of foliar bacterial plant pathogens. Annual Review of Phytopathology, Palo Alto, v.21, p.243-269, 1983.

10. IBM Corp. IBM SPSS Statistics for Windows. Version 20.0. Armonk: IBM, 2011.

11. Kado, C.I.; Heskett, M.G. Selective media for isolation of Agrobacterium, Corynebacterium, Erwinia, Pseudomonas and Xanthomonas. Phytopathology, Saint Paul, v.60, p.969-979, 1970.

12. Leymarie, J.; Vitkauskaité, G.; Hoang, H. H.; Gendreau, E.; Chazoule, V.; Meimoun, P.; Corbineau, F.; Ei-Maarouf-Bouteau, H.; Bailly, C. Role of reactive oxygen species in the regulation of Arabidopsis seed dormancy. Plant and Cell Physiology, Kyoto, v.53, n.1, p.96-106, 2012.

13. Longo, J.P.F.; Azevedo, R.B. Efeito da terapia fotodinâmica mediada pelo azul de metileno sobre bactérias cariogênicas. Revista de Clínica e Pesquisa Odontológica, Curitiba, v.6, n.3, p.249-257, 2010.

14. Machado, A.E.H. Terapia Fotodinâmica: Princípios, potencial de aplicação 
e perspectivas. Química Nova, São Paulo, v.23, n.2, p.237-243, 2000.

15. Maguire, J.D. Speed of germination aid in selection and evaluation for seedling emergence and vigor. Crop Science, Madison, v.2, n.2, p.176$77,1962$.

16. Marcuzzo, L.L.; Becker, W.F.; Fernandes, C.F. Alguns aspectos epidemiológicos da mancha bacteriana (Xanthomonas spp.) do tomateiro na região de caçador/ SC. Summa Phytopathologica, Botucatu, v.35, n.2, p.132-135, 2009.

17. Nesmith, W.C. Influence of antagonists e controlled matric potential on the survival of Pseudomonas solanacearum in four North Carolina soils. Phytopathology, Saint Paul, v.75, n.11, p.1182-1187, 1985.

18. Pelegrino, A.C.; Carolina, M.M.; Gotardo, F.A.; Simioni, A.R.; Assis, M.D.; Tedesco, A.C. Photophysical properties of crowned porphyrins. Photochemistry and Photobiology, Oxford, v.81, n.4, p.771-776, 2005.

19. Perussi, J.R. Inativação fotodinâmica de microorganismos. Química Nova, São Paulo, v.30, n.4, p.988-994, 2007.

20. Phoenix, D.A.; Sayed, Z.; Hussain, S.; Harris, F.; Wainwright, M. The phototoxicity of phenotiazinium derivaties against Escherichia coli and Staphylococcus aureus. FEMS Immunology \& Medical Microbiology, Amsterdam, v.39, n.1, p.17-22, 2003.

21. Pinton, P.C.; Rossi, M.T.; Sala, R.; Venturini, M. Photodynamic Antifungal Chemotherapy. Photochemistry and Photobiology, Oxford, v.88, n.3, p.512-522, 2012.

22. Romeiro, R.S. Bactérias Fitopatogênicas. 2.ed. Viçosa: UFV, 2005. 417p.

23. Romeiro, R.S.; Moura, A.B.; Monteiro, A.J.A.A bioassay for detection and quantification of Xanthomonas campestris in sunflower seeds. Seed Technology, Lincoln, v.20, n.1, p.94-99, 1998.
24. Tebaldi, N. D.; Ferreira, F. de S.; Oliveira, C. A. de. Tratamento fotodinâmico de sementes de tomate na inativação da bactéria Xanthomonas spp. Depositante: Universidade Federal de Uberlândia (BR/MG); Fundação de Amparo à Pesquisa do Estado de Minas Gerais - FAPEMG (BR/MG). BR 1020140169008 A2. Depósito: 8 jul. 2014.

25. Tebaldi, N.D.; Panizzi, R.C.; Sader, R. Detecção, transmissão e efeito de Xanthomonas campestris pv. campestris na qualidade fisiológica de sementes de brócolis. Summa Phytopathologica, Botucatu, v.33, n.3, p.416-418, 2007.

26. Tomm, G.O. Canola e girassol: opções de cultivo para o Brasil. Valinhos: KLFF, 2015. Disponível em: <http://www.clubeklff.com.br/publicacao/ canola-e-girassol-opcoes-de-cultivo-para-o-brasil-1207 >. Acesso em: 17 jan. 2018.

27. Tomm, G.O.; Wiethölter, S.; Dalmago, G.A.; Santos, H.P. Tecnologia para produção de canola no Rio Grande do Sul. Passo Fundo: Embrapa Trigo, 2009. (Documentos Online, 113). Disponível em: <http://www.cnpt. embrapa.br/biblio/do/p do113.htm>. Acesso em: 3 set 2017.

28. Usacheva, M.N.; Teichert, M.C.; Biel, M.A. Comparasion of the methylene blue and toluidine blue photobactericidal efficacy against gram-positive and gram-negative microorganisms. Lasers in Surgery and Medicine, New York, v.29, n.2, p.165-173, 2001

29. Usacheva, M.N.; Teichert, M.C.; Usachev, Y.M.; Sievert, C.E.; Biel, M.A. Interaction of the photobactericides Methylene Blue and Toluidine Blue with a fluorophore in Pseudomonas aeruginosa cells. Lasers in Sugery and Medicine, New York, v.40, n.1, p.55-61, 2008.

30. Villeth, G.R.; Reis, F.B.; Tonietto, A.; Huergo, L.; Souza, E.M.; Pedrosa, F.O.; Franco, O.L.; Mehta, A. Comparative proteome analysis of Xanthomonas campestris pv. campestris in the interaction with the susceptible and the resistant cultivars of Brassica oleracea. FEMS Microbiology Letters, Amsterdam, v.298, n.2, p.260-266, 2009 